\title{
ANÁLISE DA PUREZA GENÉTICA E DISCRIMINAÇÃO DE CULTIVARES DE VINCA (Catharanthus roseus (L.) G.Don) USANDO "RANDOM AMPLIFIED POLYMORPHIC DNA" EM DNA EXTRAÍDO DE SEMENTES E FOLHAS ${ }^{1}$
}

\author{
CARLOS C.E. MENEZES ${ }^{2}$, TOCIO SEDIYAMA ${ }^{3}$, MILLER B. MCDONALD E DENISE C.F.S. DIAS ${ }^{5}$
}

\begin{abstract}
RESUMO - A técnica "Random Amplified Polymorphic DNA" (RAPD) surgiu como uma ferramenta útil para testar a pureza genética e a discriminação de cultivares em muitas espécies. É uma técnica simples, rápida, relativamente de baixo custo e permite o uso de DNA extraído de sementes secas, o que é muito importante em um programa de análise de sementes. O uso desta tecnologia no teste da pureza genética pode ser muito interessante para algumas espécies, como a vinca (Catharanthus roseus (L.) G.Don), pois pouco se conhece a respeito da seqüência de seu DNA. É interessante, também, pelo fato de existir grande número de "primers" comercialmente disponíveis, que podem ser prontamente utilizados para gerar dados. Essa técnica pode ser mais facilmente utilizada para gerar padrões de bandas polimórficas suficientes para discriminar genótipos diferentes. Todavia, no presente estudo, os padrões RAPD de bandas obtidas de amostras de DNA extraído de sementes de vinca em "bulk" foram não-consistentes, o mesmo ocorrendo com o uso de DNA extraído de sementes individuais de um mesmo cultivar, o que evidencia que a técnica não é aplicável para testar a pureza genética e a discriminação de cultivares de vinca. Entretanto, os padrões de bandas RAPD gerados a partir de DNA extraído de tecido foliar de plântulas foram mais reproduzíveis e poderiam ser considerados na caracterização de cultivares. Termos para indexação: vinca, sementes, variedades, marcadores moleculares.
\end{abstract}

\section{RANDOM AMPLIFIED POLYMORPHIC DNA (RAPD) USED FOR GENETIC PURITY TEST AND VARIETY DISCRIMINATION IN VINCA (Catharanthus roseus (L.) G.Don)}

\begin{abstract}
The Random Amplified Polymorphic DNA (RAPD) technique appears useful for genetic purity testing and variety discrimination for several crops. It is simple, fast, relatively inexpensive and allows the use of DNA extracted from dry seeds, which is important in a seedquality testing program. This genetic purity testing approach may be very attractive for species such as vinca (Catharanthus roseus (L.) G.Don) because little is known concerning the DNA sequence and a number of commercial primers can be utilized to achieve polymorphic banding patterns to discriminate genotypes. However, in this study, RAPD banding patterns obtained from bulked vinca seed were not consistent. Similar inconsistent results were found for RAPD banding patterns of individual vinca seeds from the same cultivar. Thus, the low stringency requirements of RAPDs may be responsible for these irreproducible and unexpected results. In addition, this highly sensitive technique still requires further standardization of test protocol. These findings suggest that RAPD fragments obtained on electrophoretic gels are not applicable for genetic purity testing and variety discrimination in vinca flower seeds. However, RAPD banding patterns acquired from seedling leaf tissue of vinca were more reproducible.
\end{abstract}

Index terms: vinca, seeds, varieties, molecular markers.

Aceito para publicação em 31.12.2001; pesquisa financiada pela Coord. de Aperf. de Pessoal de Nível Superior - CAPES.

2 Prof. Depto. de Agron. da Fund. do Ensino Sup. de Rio Verde; 75901970, Rio Verde-GO; e-mail: cmenezes@fes.urv.br 3,5 Profs. Depto. de Fitotecnia, Universidade Federal de Viçosa; 36571-000,
Viçosa-MG; e-mail: tcyama@ufv.br; dcdias@mail.ufv.br

${ }_{4}$ Prof. Depto. of Horticulture and Crop Science, The Ohio State University, Columbus, OH 43210, USA; e-mail: mcdonald.2@osu.edu 


\section{INTRODUÇÃO}

As plantas ornamentais têm se tornado mundialmente populares, particularmente, nos países desenvolvidos. Essa popularidade está acontecendo em razão do interesse pela melhoria na qualidade de vida das pessoas, que é diretamente influenciado pela estética ambiental. Portanto, novos cultivares de plantas ornamentais, especialmente os destinados à produção de flores, estão sendo continuamente desenvolvidos pelos melhoristas e lançados no mercado. Como resultado do grande número de cultivares comercialmente disponíveis e da conseqüente semelhança genética entre eles, os testes de pureza genética e de discriminação de cultivares tornaram-se mais difíceis e complexos. Assim, há aumento na demanda de mão-de-obra qualificada para execução dessa tarefa, sem a respectiva compensação na eficiência/precisão dos resultados obtidos.

Tradicionalmente, os testes de pureza genética têm sido realizados com base nas características morfológicas, que podem ser expressas pela própria semente, ou mesmo por plântulas e, ou, plantas maduras. As características morfológicas, entretanto, não oferecem informações sobre os atributos genéticos relacionados à qualidade de grãos (alto conteúdo de óleo ou proteína) ou à resistência a estresses bióticos e abióticos incorporados nos cultivares. McDonald et al. (1994) relataram que os resultados obtidos por meio de características físicas das sementes podem ser deficientes e, ou, imprecisos, uma vez que o estresse ambiental ou as operações pós-colheita podem mascarar ou mesmo alterar aspectos morfológicos específicos. Além disto, o uso de características morfológicas na análise de sementes geralmente demanda intensa mão-de-obra, consome muito tempo e não gera resultados precisos e confiáveis. Com base no exposto, técnicas mais rápidas e confiáveis devem ser desenvolvidas e refinadas para esta finalidade.

Tecnologias mais recentes que utilizam o próprio DNA da espécie em estudo, particularmente aquelas baseadas nos protocolos da reação da polimerase em cadeia (PCR), oferecem certas vantagens. A tecnologia de PCR utiliza a enzima DNA-polimerase termoestável, que, em temperaturas alternadas, amplifica exponencialmente um determinado segmento de DNA. Em particular, a técnica PCR, associada à tecnologia denominada "Random Amplified Polymorphic DNA" (Williams et al., 1990 e Welsh \& McClelland, 1990), tem conduzido as pesquisas de identificação de cultivares em direção a uma nova geração de testes para análise da pureza genética, conhecidos como marcadores moleculares RAPD. Essa técnica usa "primers", que são oligonucleotídeos esco- lhidos, os quais se hibridizam ao DNA genômico em dois diferentes sítios, em sentidos opostos e em intervalos menores que 4.000 pares de bases (Williams et al., 1990). Pela ação da enzima Taq-DNA-polimerase, em temperaturas alternadas, o fragmento entre os dois sítios de hibridização é amplificado exponencialmente. Após a amplificação, a quantidade de DNA produzido pode ser visualizada como bandas discretas em gel de agarose submetido à eletroforese. Deste modo, alguns dos segmentos amplificados podem ser específicos de um genótipo e não de outros, e então, úteis na discriminação de cultivares.

A maioria dos estudos com RAPD é realizada com DNA obtido de tecidos foliares. Para utilizar esta técnica em um programa de tecnologia de sementes, McDonald et al. (1994) desenvolveram um protocolo para extração de DNA de sementes secas. Atualmente, existem relatos do uso de RAPD em teste de pureza genética em mais de 75 espécies, incluindo cereais, oleaginosas, muitas frutíferas, olerícolas e plantas ornamentais (Kelly \& George, 1998).

RAPD tem sido uma técnica utilizada com sucesso em teste de pureza genética e discriminação de cultivares em muitas espécies. Esses marcadores apresentam custo relativamente baixo e execução simples. Além disto, é possível a extração de DNA de sementes secas, o que torna a técnica útil para testes em laboratório de sementes. Quando tecnologistas de sementes trabalham com espécies menos estudadas, como a vinca, os marcadores RAPD tornam-se atrativos, devido ao baixo rigor requerido e também ao grande número de "primers" comercialmente disponível.

Assim, os objetivos dessa pesquisa foram: avaliar a confiabilidade da técnica RAPD em teste de pureza genética de vinca, usando DNA extraído de sementes individuais; e avaliar o potencial de marcadores RAPD para discriminação de cultivares de vinca, usando amostras de sementes em "bulk".

\section{MATERIAL E MÉTODOS}

O presente trabalho foi conduzido no Laboratório de Biologia de Sementes do "Horticulture \& Crop Science Department" da Ohio State University, Columbus, Ohio, USA, no período de 15/5 a 20/11/98.

Sementes de dez cultivares de vinca "Peppermint", "Strawberry", "Blue Pearl", "Blush Cooler", "Rose Cooler", "Raspberry", "Grape Cooler", "Orchid Cooler", "Coconut Cooler" e "Pink White Eye" foram obtidas da companhia de sementes Ball Seed Company, West Chicago, IL. Essas sementes foram usadas em um estudo preliminar, a fim de sele- 
cionar cinco cultivares que apresentassem os mais elevados níveis de polimorfismo.

Determinação da pureza genética - dez sementes de cada uma das dez variedades foram, individualmente (sem repetições), maceradas entre duas folhas de papel alumínio, com o uso de pistilo de porcelana. A partir da maceração, as etapas seguintes para extração do DNA seguiram o protocolo descrito por McDonald et al. (1994). Esse protocolo constitui na adição de $100 \mathrm{ml}$ do tampão de extração [Tris- $\mathrm{HCl}$ (pH 7,5) 200mM, $\mathrm{NaCl} 288 \mathrm{mM}$, ácido etilenodiamino tetraacético (EDTA) $25 \mathrm{mM}$ e dodecil sulfato de sódio (SDS) $0,5 \%$ ] nas amostras de sementes maceradas. Após a homogeneização com a ponta da pipeta, um volume de $900 \mu 1$ do tampão de extração foi adicionado, para obter um total de $1 \mathrm{ml}$. A amostra foi ligeiramente agitada em vórtex, durante 10 segundos, e centrifugada por 10 minutos a 10.144 x g. Em se-

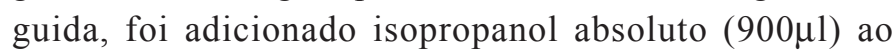
sobrenadante e deixado em temperatura ambiente, durante dois minutos, para precipitação do DNA. Posteriormente, o DNA foi centrifugado, por sete minutos, a 10.144 x g, para formação de "pellet". Este foi seco, em dessecador a vácuo, por 15 minutos. Após a secagem, o DNA foi ressuspendido em $150 \mu 1$ de TE [Tris-HCl (pH 7,5) 10mM, EDTA 1mM].

A quantificação do DNA foi realizada pela leitura em espectrofotômetro HP 8452A Diode Array (Hewlett Packard, Waldbronn, GER), utilizando leituras de densidade ótica (OD) de 260 e $280 \mathrm{~nm}$. O primeiro valor é relativo à concentração de DNA, enquanto a razão $\mathrm{OD}_{260} / \mathrm{OD}_{280}$ refere-se à pureza da amostra.

Discriminação de cultivares - cinco cultivares de vinca "Peppermint", "Blue Pearl", "Blush Cooler", "Rose Cooler" e "Raspberry", que mostraram suficiente polimorfismo, foram selecionados após realização do estudo preliminar. Aproximadamente 100 sementes $(100 \mathrm{mg}$ ) de cada cultivar foram maceradas com o uso de pistilo e cadinho de porcelana. A extração total de DNA, a quantificação e a diluição foram realizadas conforme descrito anteriormente para determinação da pureza genética, no ensaio preliminar. Para extrair DNA de tecidos foliares, foram selecionadas 20 plântulas de cada cultivar, com três semanas após emergência. Suas folhas foram coletadas, cortadas logo em seguida em pedaços pequenos e, então, uniformemente misturadas. Posteriormente, a extração de DNA foi realizada por meio do método CTAB (Saghai-Maroof et al., 1984), utilizando 4g de tecido foliar. A quantificação do DNA e a posterior diluição seguiram o mesmo procedimento descrito para determinação da pureza genética em sementes individuais.
Amplificação de DNA - após diluição para aproximadamente $3 \mathrm{ng} \mathrm{\mu l}^{-1}, 3 \mathrm{ml}$ de cada amostra de DNA foram adicionados a um tubo de reação contendo $24 \mu \mathrm{l}$ de solução de PCR [Tris- $\mathrm{HCl}$ (pH 8,4) 20mM; KCl 50mM; $\mathrm{MgCl}_{2} 3 \mathrm{mM}$ 200 $\mu \mathrm{M}$ de cada dATP, dCTP, dGTP, dTTP, 1,5 unidade de' Taq-DNA-Polimerase (Perkin Elmer, Foster City, CA) e 0,4 $\mu \mathrm{M}$ primer]. Quatro "primers" (decâmeros) (Ransom Hill Bioscience, Inc., Ramona, CA) que se mostraram eficientes na amplificação de DNA em estudos preliminares foram usados: 262 (CGC CCC CAG T), 244 (CAG CCA ACC G), 07 (CGG CCA CTG T) e 01 (CGG CCC CTG T).

Para determinação da pureza genética no ensaio preliminar, foram preparadas 400 reações, utilizando DNA de sementes individuais (10 sementes X 10 cultivares $X$ quatro "primers"). A partir dos resultados obtidos, os cinco cultivares foram selecionados para o estudo posterior. A discriminação de cultivares foi realizada com DNA de sementes em “bulk”. Foram preparadas 40 reações (cinco cultivares X duas reações X quatro "primers").

Os tubos de reação com a mistura completa para a amplificação de DNA e um controle que continha todos os reagentes, exceto DNA, receberam uma gota de óleo mineral para minimizar a evaporação durante a PCR. Após o preparo, os tubos foram agitados em um vórtex por aproximadamente três segundos, em seguida ligeiramente centrifugados para precipitar todo o material e, então, colocados em termociclador de DNA 480 (Perkin Elmer, Fairfield, OH). O equipamento foi programado para repetir 40 vezes o seguinte ciclo de temperaturas: $94^{\circ} \mathrm{C}$, um minuto; $40^{\circ} \mathrm{C}$, um minuto; e $72^{\circ} \mathrm{C}$, dois minutos. Foram ajustadas, também, a temperatura inicial de $94^{\circ} \mathrm{C}$, por três minutos, e a temperatura final de $72^{\circ} \mathrm{C}$, por 15 minutos, para desnaturação e extensão do DNA, respectivamente. Após aproximadamente quatro horas, os tubos foram removidos do termociclador e centrifugados a $10.144 \mathrm{x}$ g por, aproximadamente, 15 segundos, evitando, assim, qualquer perda de material. Para aferir a repetibilidade das amostras, foram preparados, separadamente, dois tubos para cada um dos cultivares, contendo todos os reagentes na mesma concentração, os quais foram submetidos às mesmas condições de amplificação e eletroforese. Esta metodologia foi realizada com o DNA extraído de tecidos de sementes e de tecidos foliares. O experimento foi repetido três vezes, para confirmação dos resultados.

Eletroforese - foi utilizado gel de agarose na concentração de $1,5 \%$, contendo $89 \mathrm{mM}$ Tris $(\mathrm{pH} 8,0), 89 \mathrm{mM} \mathrm{H}_{2} \mathrm{BO}_{4}$, $2 \mathrm{mM}$ EDTA e $1,34 \mathrm{mM}$ brometo de etídio. O brometo de etídio se liga ao DNA, e este complexo fluoresce na presença de luz 
ultravioleta. Foram adicionados $2 \mu \mathrm{l}$ de corante $(30 \%$ de glicerol e $0,25 \%$ de azul de bromofenol) à reação de amplificação, e uma alíquota de $10 \mu 1$ da amostra amplificada foi aplicada no gel. A eletroforese foi conduzida a uma voltagem constante de $3,24 \mathrm{~V} / \mathrm{cm}$, durante aproximadamente duas horas. Em seguida à eletroforese, os produtos amplificados de DNA foram visualizados e fotografados com o uso de um transluminador modelo 3-3100 (Fotodyne, Hartland, WI).

\section{RESULTADOS E DISCUSSÃO}

Após a avaliação preliminar dos quatro "primers" nos dez cultivares estudados, foram escolhidos os cinco cultivares que apresentavam as maiores freqüências de bandas
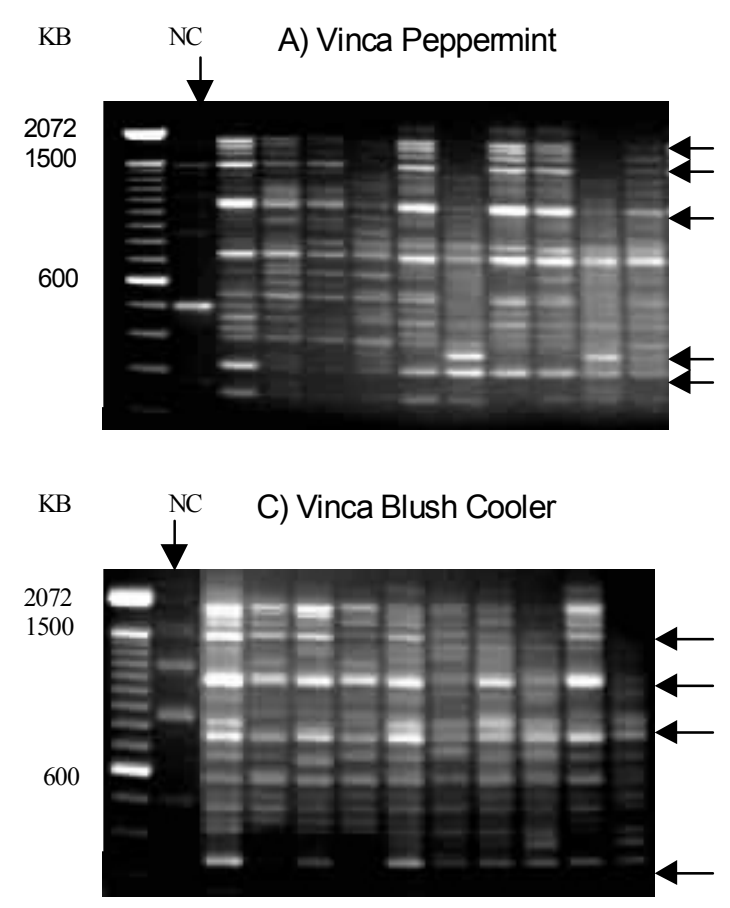

polimórficas, para estudos posteriores (Figura 1). Aproximadamente $35 \%$ de bandas polimórficas foram encontradas entre sementes individuais da mesma variedade (Figura 1). Considerando que a vinca é uma espécie predominantemente de auto-fecundação, padrões monomórficos de bandas eram esperados, pois demonstraria alto nível de pureza genética.

Esses resultados evidenciam, na verdade, alto nível de heterogeneidade entre esses cultivares de vinca, presumindose que o protocolo RAPD seja reproduzível entre sementes. Entretanto, quando foram preparadas duas reações, usando DNA de um mesmo cultivar em "bulk", em condições idênticas de preparo e amplificação em PCR e, posteriormente, aplicadas lado a lado no gel, para verificar a repetibilidade, os resultados não foram consistentes (Figura 2). Embora os

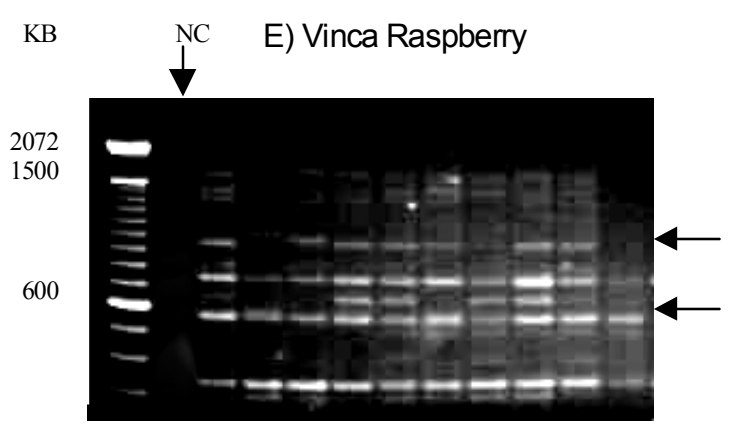

FIG. 1. Polimorfismo RAPD derivado de dez sementes de vinca individuais de cinco cultivares.

O "primer" 01 foi usado para amplificar os cultivares A, B, C, D; e o "primer" 262 foi usado para amplificar o cultivar E. NC $=$ controle negativo; $\mathbf{K B}=$ hilo bases (mil pares de bases nitrogenadas).

As setas indicam o polimorfismo entre sementes do mesmo cultivar. 
KB

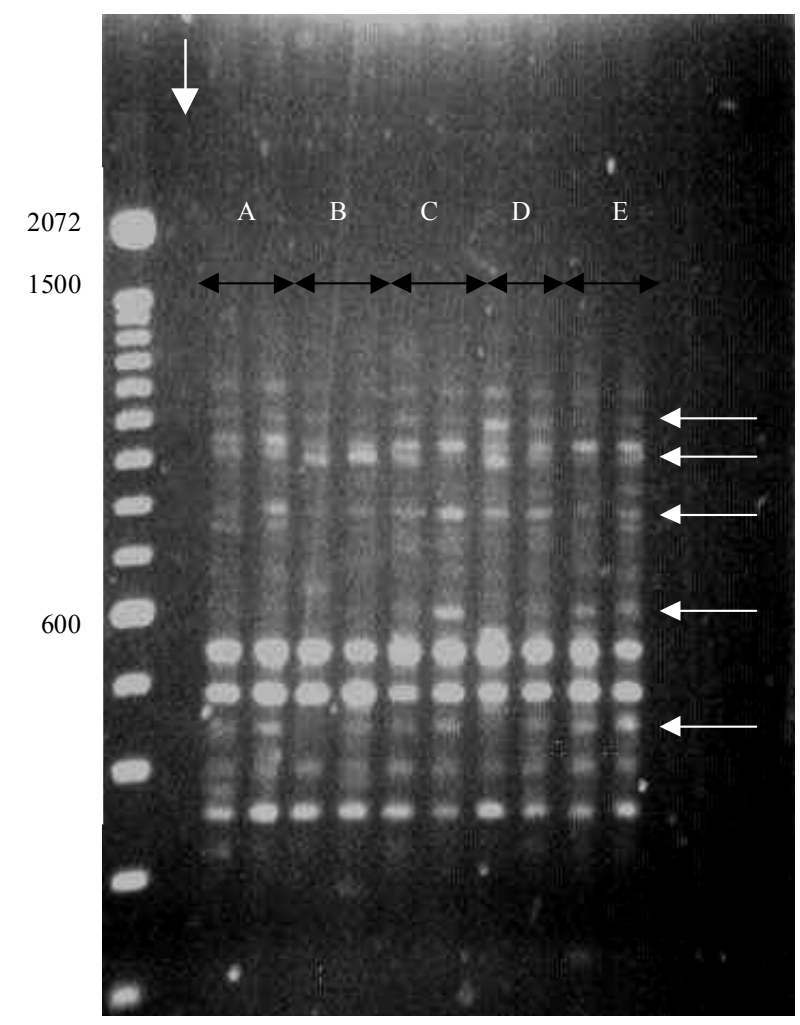

FIG. 2. Polimorfismo RAPD entre o mesmo cultivar de vinca, usando DNA extraído de sementes em "bulk" e aplicado no gel em pares.

O "primer" usado para amplificação foi o 01. A) Vinca "Peppermint", B) vinca "Blue Pearl", C) vinca "Blush Cooler", D) vinca "Rose Cooler" e E) vinca "Raspberry". $\mathbf{N C}=$ controle negativo; $\mathbf{K B}=$ hilo bases (mil pares de bases nitrogenadas)

As setas indicam o polimorfismo entre a mesma cultivar.

resultados tenham sido mais consistentes quando comparados com os das amostras de DNA obtido de sementes individuais, a reprodutibilidade alcançada neste trabalho não foi, ainda, tão consistente quanto os resultados publicados para outras espécies, usando DNA obtido de sementes em "bulk" (Shatters-Jr. et al., 1995; Marcos-Filho et al.,1997 e Zhang et al., 1997).

Verifica-se, portanto, que o procedimento que usa o DNA extraído de sementes secas de vinca não produziu resultados reprodutíveis e pode conduzir a conclusões incorretas em relação à pureza genética e à discriminação de cultivares.

Staub et al. (1996) relataram que a técnica RAPD é altamente sensível, requerendo como pré-requisito a padronização do protocolo para obtenção de resultados consistentes. Neste contexto, a extração do DNA torna-se uma etapa extremamente importante, uma vez que a seqüência-alvo deve estar acessível ao "primer". Caso contrário, todas as etapas subseqüentes não serão reprodutíveis, devido a pareamentos errados.

McDonald et al. (1994) concluíram que o procedimento de extração do DNA de sementes secas foi útil para algumas espécies (milho, algodão, soja, trigo e trevo-forrageiro), porém, também concluíram que este protocolo não é universalmente aplicável para todas as espécies, pois não gerou resultados consistentes para sementes de amendoim. Acredita-se que o procedimento de extração de DNA em sementes de vinca não produziu DNA com qualidade suficiente para anelamento consistente do "primer". Assim, os resultados não foram consistentes.

Os padrões obtidos com o uso de DNA extraído de folhas foram mais consistentes. Estes resultados foram avaliados quando dois tubos de reações, ambos contendo todos os reagentes, foram preparados separadamente, submetidos às mesmas condições de amplificação e aplicados no gel lado a lado, em pares (Figura 3). O resultado obtido está de acordo

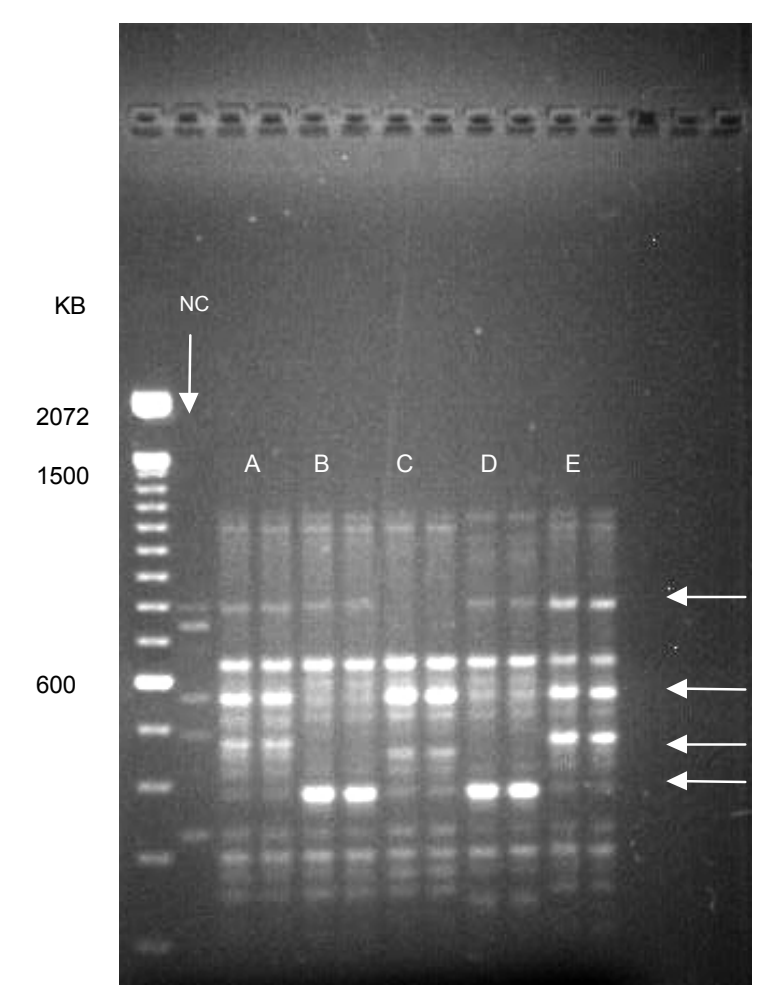

FIG. 3. Repetibilidade das bandas RAPD no mesmo cultivar de vinca, usando DNA extraído de folhas e aplicado no gel em pares.

O "primer" usado para amplificação foi o 07. A) Vinca "Peppermint", B) vinca "Blue Pearl", C) vinca "Blush Cooler", D) vinca "Rose Cooler" E) vinca "Raspberry". $\mathbf{N C}=$ controle negativo; $\mathbf{K B}=$ hilo bases (mil pares de bases nitrogenadas)

As setas indicam o polimorfismo entre diferentes cultivares. 
com a afirmativa de Ferreira \& Grattapaglia (1996), que relataram que vários tipos de tecidos de plantas podem ser usados como fonte de DNA, inclusive sementes. Entretanto, tecidos vegetais em sua fase de crescimento ativo promovem os melhores resultados.

Para verificar a influência da qualidade do DNA nos resultados, o DNA de folhas de plântulas foi extraído e os perfis das bandas observadas no gel foram comparados com aqueles obtidos de sementes (Figura 4).

Foram também utilizadas as leituras no espectrofotômetro das concentrações de DNA, para verificar sua qualidade. As leituras obtidas do DNA extraído de sementes individuais variaram de 150 a $250 \mathrm{ng} \cdot \mu \mathrm{l}^{-1}$, enquanto a razão $\mathrm{OD}_{260} / \mathrm{OD}_{280}$ variou de 1,4 a 1,6. Para sementes em "bulk", as concentrações variaram de 250 a $600 \mathrm{ng} . \mu \mathrm{l}^{-1}$ e a razão $\mathrm{OD}_{260} / \mathrm{OD}_{280}$ variou de 1,3 a 1,5. Quando o DNA foi extraído de tecido foliar, as concentrações variaram de 400 a $800 \mathrm{ng} . \mu \mathrm{l}^{-1}$ e a razão $\mathrm{OD}_{260} / \mathrm{OD}_{280}$ variou de 2,0 a 2,3. Razões $\mathrm{OD}_{260} / \mathrm{OD}_{280}$ superiores a 1,8 indicam DNA de melhor qualidade, principalmente DNA menos contaminado por proteínas.

Há pouca dúvida em relação ao fato de RAPD poder ser útil para testar a pureza genética e discriminar cultivares em certas situações. A técnica não requer conhecimento prévio da seqüência-alvo do DNA, o que a torna interessante para

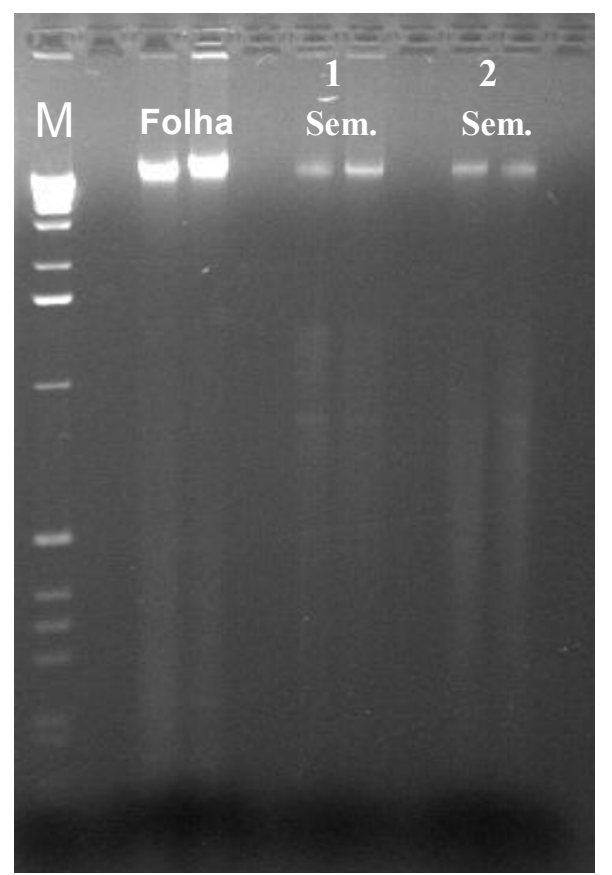

FIG. 4. Comparação entre a qualidade do DNA extraído de tecido foliar e de sementes secas de vinca.

1) Método "proteinase K" e 2) método rápido. espécies com pouca informação genética disponível, como é o caso da vinca. Entretanto, o baixo rigor requerido pela técnica pode causar resultados irreprodutíveis e inesperados em alguns casos, especialmente para alguns tipos de tecidos (Riedy et al., 1992 e Heun \& Helentjaris, 1993).

Fowler \& Kijas (1994) enfatizaram que a contínua pesquisa com RAPD tem evidenciado claramente que a técnica é limitada, o que pode ser verificado pela dificuldade em reproduzir perfis equivalentes entre laboratórios.

Segundo Smith \& Register (1998), RAPD é a tecnologia baseada em DNA menos aceita para identificação de cultivares e teste da pureza genética. De acordo com os autores, a limitação da técnica é função principalmente dos problemas de padronização.

Este estudo demonstra que o padrão de bandas RAPD obtido de tecidos de sementes foi irreprodutível, enquanto aquele obtido do tecido foliar foi mais reprodutível.

\section{CONCLUSÕES}

- Não se deve conduzir trabalhos com marcadores RAPD para análise da pureza genética e discriminação de cultivares de vinca utilizando sementes secas como fonte de DNA;

- deve-se utilizar preferencialmente DNA extraído de tecidos foliares de plântulas de vinca para discriminação de variedades e determinação de pureza genética;

- pesquisas sobre o procedimento de extração de DNA e, ou, condições mais rigorosas durante o processo devem ser realizadas, no sentido de tornar a técnica aplicável às sementes de vinca e outras espécies em que os resultados obtidos pela técnica RAPD não são consistentes.

\section{REFERÊNCIAS}

FERREIRA, M.E. \& GRATTAPAGLIA, D. Introdução ao uso de marcadores moleculares em análise genética. 2.ed. Brasília: EMBRAPA-CENARGEN, 1996. 220p.

FOWLER, J.C.S. \& KIJAS, J.M.K. Current molecular methods for plant genome identification. Australasian Biotechnology, Gardenvale, v.4, p.153-157, 1994.

HEUN, M. \& HELENTJARIS, T. Inheritance of RAPDs in F hybrids of corn. Theoretical and Applied Genetics, Berlin, v.85, n.8, p.961-968, 1993.

KELLY, A.F. \& GEORGE, R.A.T. Cultivar identification. In: Encyclopaedia of Seed Production of Word Crops. London: John Wiley \& Sons Ltd., 1998. p.88-111.

LOWE, A.J.; HANOTTE, O. \& GUARINO, L. Standardization of molecular genetic techniques for the characterization of germoplasm collections: the case of random amplified 
polymorphic DNA (RAPD). Plant Genetic Resources Newsletter, Rome, n.107, p.50-54, 1996.

MARCOS-FILHO, J · MCDONALD, M.B ; TEKRONY, D M \& ZHANG, J. RAPD fragment profiles from deteriorating soybean seeds. Seed Technology, Lincoln, v.19, n.1, p.34-44, 1997.

MATSUNAGA, M. A indústria da flor no mundo e o comércio internacional do Brasil. Revista Brasileira de Horticultura Ornamental, Campinas, v.3, n.2. p.1-4, 1997.

MCDONALD, M.B.; ELLIOT, L.J. \& SWEENEY, M.P. DNA extraction from dry seeds for RAPD analyses in varietal identification studies. Seed Science \& Technology, Zürich, v.22, n.2, p.171-176, 1994.

RIEDY, M.F.; HAMILTON, W.J. \& AQUADRO, C.F. Excess of non-parental bands in offspring from known primate pedigrees assayed using RAPD PCR. Nucleic Acids Research, Oxford, v.20, n.12, p.918-931, 1992.

SAGHAI-MAROOF, M.A.; SOLIMAN, K.M.; JORGENSEN, R.A. \& ALLARD, R.W. Ribosomal DNA spacer-length polymorphisms in barley: Mendelian inheritance, chromosomal location, and population dynamics. Proc. Natl. Acad. Sci., Washington, v.81, p.8014-8018, 1984.

SHATTERS-Jr., R.G.; SCHWEDER, M.E.; WEST, S.H.; ABDEL-
GHANY, A. \& SMITH R.L. Environmentally induced polymorphisms detected by RAPD analysis of soybean seed DNA. Seed Science Research, Wallingford, v.5, n.2, p.109$116,1995$.

SMITH, J.S.C. \& REGISTER, J.C. Genetic purity and testing technologies for seed quality: a company perspective. Seed Science Research, Wallingford, v.8, n.2, p.285-293, 1998.

STAUB, J.; BACHER, J. \& POETTER, K. Sources of potential errors in the application of random amplified polymorphic DNAs in cucumber. HortScience, Alexandria, v.31, n.2, p.262-266, 1996.

WELSH, J. \& MCCLELLAND, M. Fingerprinting genomes using PCR with arbitrary primers. Nucleic Acids Research, Oxford, v.18, n.24, p.7213-7218, 1990.

WILLIAMS J.G.K., KUBELIK A.R., LIVAK K.J., RAFALSKI J.A \& TINGEY S.V. DNA polymorphisms amplified by arbitrary primers are useful as genetic markers. Nucleic Acids Research, Oxford, v.18, n.20, p.6531-6535, 1990.

ZHANG J., MCDONALD M.B. \& SWEENEY M.P. Testing for genetic purity in petunia and cyclamen seed using random amplified polymorphic DNA markers. HortScience, Alexandria, v.32, n.2, p.246-247, 1997. 